\title{
Dimensionality of the Pittsburgh Sleep Quality Index: a systematic review
}

\author{
Md Dilshad Manzar ${ }^{1,2^{*}}$ (D) Ahmed S. BaHammam, ${ }^{3,4}$, Unaise Abdul Hameed ${ }^{5}$, David Warren Spence ${ }^{6}$, \\ Seithikurippu R. Pandi-Perumal ${ }^{3,4}$, Adam Moscovitch ${ }^{7}$ and David L. Streiner ${ }^{8,9}$
}

\begin{abstract}
Background: The Pittsburgh Sleep Quality Index (PSQI) dimensionality is much debated, with the greatest number of reported factor structures. Therefore, this review appraised the methodologies of studies investigating the factor structure of the PSQI.

Material and methods: MEDLINE, PsycInfo, AJOL, BASE, Cochrane Library, Directory of Open Access Journals (Lund University), CINAHL, and Embase were searched systematically to include articles published till 23rd March, 2018. The articles with the objective of factor analysis of the PSQI (20 articles) or with a major section on the same subject (25 articles) were included. There was no limitation about participant characteristics. Descriptive analysis of articles for measures of the suitability of the data for factor analysis, details of the exploratory factor analysis (EFA) and details of the confirmatory factor analysis (CFA) was performed.
\end{abstract}

Results: The analysis used by the majority did not employ the simplest scheme for interpreting the observed data: the parsimony principle. Other shortcomings included under- or non-reporting of sample adequacy measures (11 out of 45 articles), non-use of EFA (20 out of 45 articles), use of EFA without relevant details, non-use of CFA (11 out of 45 articles), and use of CFA without relevant details. Overall, 31 out of 45 articles did not use either EFA or CFA.

Conclusion: We conclude that the various PSQI factor structures for standard sleep assessment in research and clinical settings may need further validation.

Trial registration: Not applicable because this was a review of existing literature.

Keywords: Confirmatory factor analysis, Dimensionality, Exploratory factor analysis, Model fit, Systematic review, Sleep

\section{Background}

Population-based epidemiological studies have confirmed that sleep disorders occur frequently in almost every country [1-3]. Complaints of disturbed or poor quality sleep are also exceedingly common among patients presenting to all specialties of medicine [4-6]. The most common sleep disorders are insomnia, circadian rhythm sleep disorders, obstructive sleep apnea, sleep-disordered breathing, hypersomnia, daytime sleepiness, parasomnias, and restless legs syndrome [4-7]. Untreated sleep disorders may lead to potentially life-threatening symptoms. It

\footnotetext{
* Correspondence: m.manzar@mu.edu.sa; md.dilshadmanzar@gmail.com ${ }^{1}$ Department of Nursing, College of Applied Medical Sciences, Majmaah University, Al Majmaah, Kingdom of Saudi Arabia

${ }^{2}$ Department of Biomedical Sciences, College of Medicine and Health Sciences, Mizan-Tepi University (Mizan Campus), Mizan-Aman, Ethiopia Full list of author information is available at the end of the article
}

is now recognized that far from being only a consequence of medical illnesses, sleep disorders are often primary drivers of other illnesses. Sleep disturbance is linked to neurocognitive dysfunctions, including attention deficits, impaired cognitive performance, depression, anxiety, stress, and poor impulse control. These disturbances are in turn linked to sympathetic activity changes and an increased risk of cardiovascular and cerebrovascular diseases $[4,5,8]$. These impairments have wider consequences in patients' lives. Poor sleep severely impairs daytime performance, both socially and at work, and increases the risk of occupational and automobile accidents, poor quality of life, and poor overall health $[4,5,9-11]$.

(c) The Author(s). 2018 Open Access This article is distributed under the terms of the Creative Commons Attribution 4.0 International License (http://creativecommons.org/licenses/by/4.0/), which permits unrestricted use, distribution, and reproduction in any medium, provided you give appropriate credit to the original author(s) and the source, provide a link to the Creative Commons license, and indicate if changes were made. The Creative Commons Public Domain Dedication waiver (http://creativecommons.org/publicdomain/zero/1.0/) applies to the data made available in this article, unless otherwise stated. 


\section{Role of subjective measurement}

The ever-increasing list of problems known to be caused by sleep dysfunction has led to recognition that poor sleep has a complex relationship with overall health. It is now appreciated that disturbed sleep interacts bi-directionally with numerous neurological, physiological, psychological, and behavioral factors [4, 12-14]. The central role of sleep in overall health has thus underscored the need for both reliable, validated subjective tools and objective polysomnographic (PSG) assessment in modern medical practice. While these represent very different diagnostic approaches, they are nevertheless complementary in as much as subjective tools account for psychological and behavioral manifestations not assessed by PSG. Self-rating questionnaires such as the Pittsburgh Sleep Quality Index (PSQI) have an important role in sleep health assessment in both clinical and research settings $[4,15,16]$. These questionnaires have the advantages of cost effectiveness, high patient compliance, and ease of administration. Perhaps more importantly, since such questionnaires are selfexplanatory and do not require supervision, they reduce demand on medical specialists' time [5]. Given the important diagnostic role of rating scale questionnaires, it is essential that their reliability and validity be established beyond doubt. A key element of this quality assurance is psychometric confirmation of the questionnaires' dimensionality, i.e., whether the questionnaire's items are all correlated and representative of factors affecting sleep quality $[4,15]$. This review critically appraises the evidence for dimensionality of one of the most widely used self-rating instruments of sleep quality, the PSQI $[4,15,17]$.

\section{Pittsburgh Sleep Quality Index}

The PSQI is the most widely used sleep health assessment tool in both clinical and non-clinical populations. The original 1989 article describing the Index has, since 26-06-2015, had 1545, 7863, 4962, and 4554 citations on PMC, Google Scholar, ResearchGate, and Web of Science, respectively. It is also possibly the most widely translated sleep questionnaire. The PSQI consists of 24 questions or items to be rated (0-3 for 20 items while 4 items are open-ended), 19 of which are self-reported and 5 of which require secondary feedback from a room or bed partner. Only the self-reported items (15 rated as 0 3 while 4 open-ended) are used for quantitative evaluation of sleep quality as perceived by the patient. The open-ended items are also finally scored as structured categorical values (rated at $0-3$ ) as per the range of values reported for them by the patient. These 19 selfreported items are used to generate categorical scores representing the PSQI's 7 components. The individual component scores each assess a specific feature of sleep. Finally, the scores for each component are summed to get a total score, also termed the global score (range: 0 to 21). This score provides an efficient summary of the respondent's sleep experience and quality for the past month [12].

\section{Validation and reliability measures of the Pittsburgh Sleep Quality Index}

The PSQI is possibly the most rigorously validated tool used in sleep diagnostics $[4,5,15-17]$. Of the many psychometric studies carried out on the PSQI, $75 \%$ have reported an internal consistency in the ideal range for within- and between-group comparisons but not for comparisons made between questionnaires for individual patients [4]. Mollayeva et al. [4] performed a meta-analysis and found strong evidence for the PSQI's reliability and validity. Further, the meta-analysis revealed a moderately positive evidence for the questionnaire's structural validity across a variety of samples. The PSQI was found to have known-group validity, and, while some studies showed methodological weaknesses in this regard, its convergent and divergent validity were generally confirmed.

\section{Factor analysis}

A tool's dimensionality is evaluated by factor analysis. Factor analysis attempts to discover patterns in a set of variables based on shared variance [18]. A key goal of this analysis is identifying the simplest and most parsimonious means for interpreting and representing observed data [19]. More specifically, the procedure seeks to use measured variables to infer the smallest number of unobserved or latent variables that can still account for the observable variables [20]. The mathematical operations are broadly categorized into 2 sub-groups: exploratory factor analysis (EFA) and confirmatory factor analysis (CFA). EFA aims to find the smallest number of common latent factors that can account for the correlations [21]. CFA is then employed to test the relationship between the observed variables and their underlying latent factors [15]. Factor analysis is useful for studies involving many variables that can be reduced to a smaller set, such as questionnaire items or a battery of tests. The goal of this process is identifying the concepts underlying a phenomenon and thus facilitating interpretations.

\section{Dimensionality of the PSQI}

The PSQI's dimensionality is much debated, with many studies supporting multiple factors and some supporting unidimensionality [4, 15-17]. Among sleep diagnostic tools, the PSQI has the greatest number of reported factor structures [15]. The intensity of discussion around the topic of the dimensionality of the PSQI is reflected in the publication of 45 articles on the subject since 2006 [15]. As the PSQI components are structured categorical variables scored $0-3$, therefore the factor analysis should ideally begin with a polychoric 
correlation matrix. However, most of the programs do use a Pearson correlation matrix. It may be one of the reasons for the discrepancy among studies. Some evidence suggests that some studies may have over-factored the PSQI [15]. Several reviews have concluded that many previous efforts to investigate the PSQI's factor structure have suffered from nonparsimonious methodologies [4, 15, 17, 22-46]. Given a choice between close fit and parsimony (i.e., model with fewer latent factors), the latter may be preferred [47]. Manzar et al. [15] used an innovative strategy of performing comparative CFA of all the documented PSQI models on a discrete sample to disprove the questionnaire' soft-reported multidimensionality and heterogeneity. However, the study had the important limitation of being unable to address inter-software, inter-sample, and inter-model differences [15]. Mollayeva et al. [4] mentioned procedural discrepancies in the studies investigating the PSQI factor structures without providing further details. Approximately 30 distinct PSQI models have been proposed in the literature. Of these models, 7 were 1 -factor, 17 were 2 -factor, 4 were 3 -factor, 1 was 4-factor and 2 were second order models [15-17, 2246, 48-53]. The current state of the literature, with its broad range of suggested factor structure models, represents an impediment to an efficient consideration of the PSQI's use. There evidently exists a need for a thorough appraisal of the procedural details and application of standard practices in the previous methodological studies of the PSQI. Such an investigation is indispensable for streamlining the debate about the PSQI's heterogeneity.

\section{Practical implication of the heterogeneity of the Pittsburgh Sleep Quality Index}

One consequence of the PSQI's presumed heterogeneity is the possible attenuation of its practical application in clinical diagnostics [15]. A questionnaire's dimensionality directly affects the reporting of its intended measures. Currently, however, very few efforts have been undertaken to validate the PSQI's disparate models in either research or clinical settings. This is possibly related to the choice of the appropriate PSQI model for a particular sample. Previous attempts by Hancock and Larner [54] and Yurcheshen et al. [55] to test the disparate PSQI models did not adequately address the reason(s) for the specific model's selection. In fact, both studies used a 3-factor PSQI model initially reported to be valid in a different population [22, 54-56]. Such reports using unrelated PSQI models will complicate inter-study comparisons for the PSQI-based measures. The goal of the present systematic review is to help develop strategies for managing the methodological discrepancies in the PSQI factor analysis and reporting of the PSQI-based sleep assessment. An additional goal is to provide possible guidelines for factor analyses of questionnaires in general and sleep inventories in particular.

\section{Material and methods}

\section{Literature search scheme}

All articles available online on 23-03-2018 were included. The comprehensive search strategy was planned in consultation with epidemiological experts, information technologists, and sleep scientists. We searched 8 electronic databases: CINAHL, Bielefeld University (BASE: Bielefeld Academic Search Engine), Cochrane Library, Directory of Open Access Journals (Lund university), Embase, Medline, PsycInfo, and African Journals On Line (AJOL).

To minimize inclusion of irrelevant articles, we searched for a combination of 2 keywords (Pittsburgh Sleep Quality Index/PSQI with dimensionality/dimension/factor model/ factor analysis/factor structure/domain/Exploratory factor analysis/EFA/Confirmatory factor analysis/CFA). Seventyeight articles were initially identified (Fig. 1). Thirty four articles; 30 duplicates, 3 with reasons (Factor analysis details were missing) and 1 for unavailability of full-length article were removed.

\section{Selection criteria}

Forty five full-length peer-reviewed articles were used. Forty three articles were in English, and 1 each was in Spanish and Chinese. We e-mailed the lead author of the Spanish article an English translation of the section covering factor analysis. It was included after gaining the author's approval. The lead author of the Chinese article provided translation of the factor analysis section, therefore it was also included. The articles' reference lists were thoroughly reviewed for other relevant publications. There were no restrictions on the type or age range of the population covered. We only included articles that had a primary objective of exploring and/or confirming dimensionality (20 studies) and articles that reported multiple indices of psychometric properties with a substantial section devoted to factor analysis (25 studies) (Fig. 1).

\section{Data extraction}

The measures used to present the factor analysis findings were grouped in three broad categories; measures of the suitability of the data for factor analysis (Table 1), summary of the exploratory factor analysis conditions (Table 2) and summary of the confirmatory factor analysis conditions (Table 3). Descriptive analysis of articles for measures of these three categories was performed. Meta-analysis was not conducted as the included studies were heterogeneous in methods and statistical analyses used.

\section{Results}

Sample description, sample size, and measures of the suitability of the data for factor analysis

The factor analysis of the PSQI has been reported on diverse samples including university/college students in Nigeria, India, Chili, Chinese, Ethiopia, Peru and Thailand, pregnant women, community dwelling adults and older 


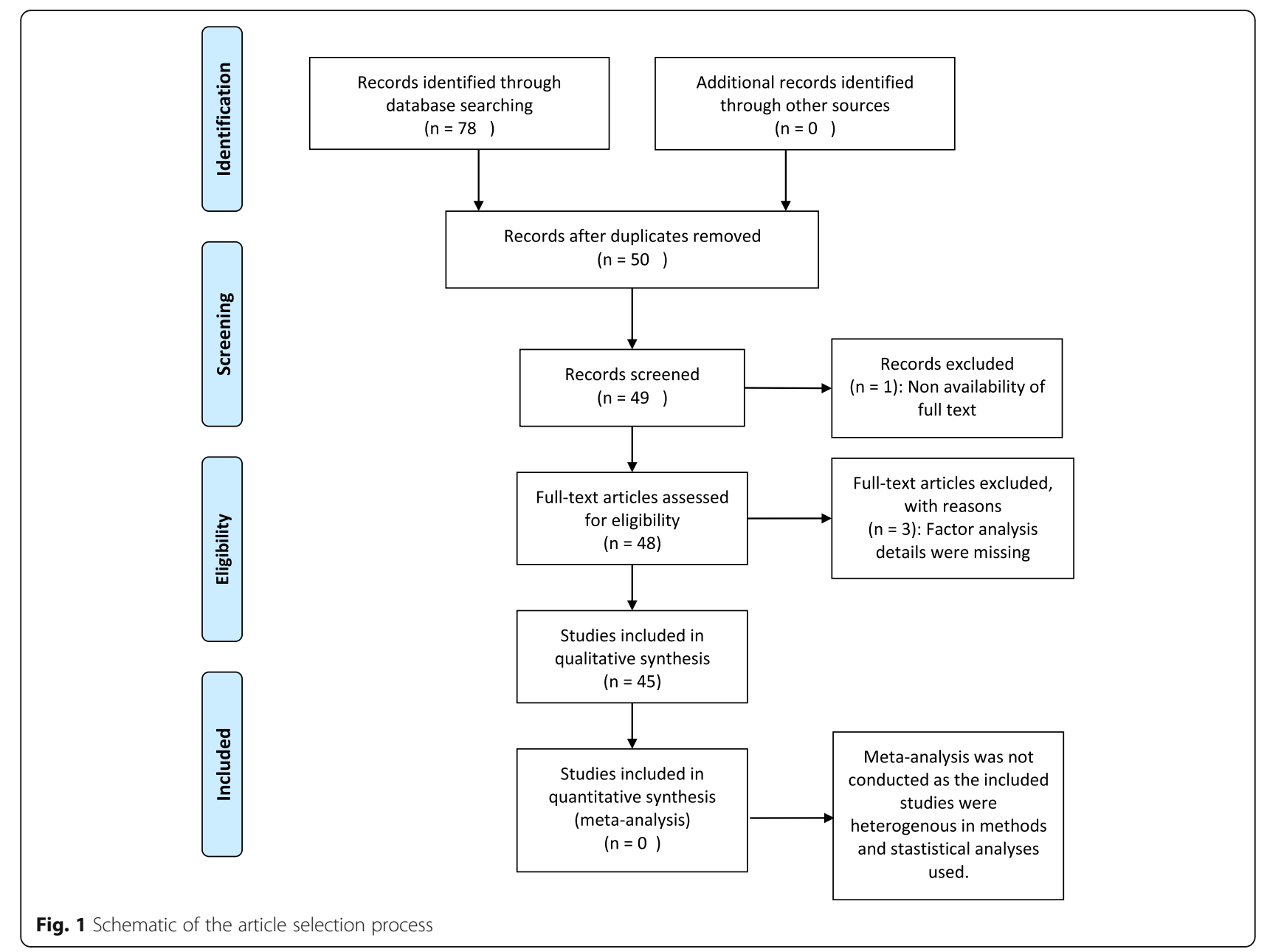

adults in America, Australia, China, Ethiopia, Spain, Portugal, Iranian health professionals, adolescents and young adults $[15-17,23,24,26-28,31,34,36,39,41,44$, $45,52,53,57-60]$. Moreover, it has been reported for patient population with breast cancer, Crohn's disease, depression, diabetes, women with hot flashes, Taiwanese insomniacs, post-traumatic stress disorder, Trauma exposed veterans, temporo-mandibular disorder, traumatic brain injury, fibromyalgia, arthritis, chronic fatigue syndrome, psychiatric disorders and renal transplant patients [25, 27, 29, $30,32,33,35,37,38,40,42,43,46,49,51,61-65$ ].

Few of the studies reviewed had large sample sizes (Table 1). The sample sizes of studies reporting the PSQI factor structures differed widely, ranging from 105 to 2840 (Table 1) [38, 44, 66]. Only 3 studies reported determinant scores and anti-image values (Table 1) [15-17]. We counted the number of studies reporting any of the following 5 indices: Kaiser-Meyer-Olkin (KMO) Measure of Sampling Adequacy, Bartlett's sphericity test, determinant score, anti-image, and component correlations (Table 1). Eighteen studies reported both the KMO and Bartlett's sphericity test $[15-17,25,39,43-45,51-53,57-59,61$,
$64,65,67]$, reported inter-item correlations [16, 22, 24, 25 , $27,29,30,32-34,36,37,41,42,45,46,50,53,57,64-67]$, and 11 studies did not report any index [23, 26, 28, 31, 35, $38,40,49,60,62,63]$.

\section{Exploratory factor analysis}

Twenty articles did not report having carried out EFA $[15,23,26,29,32-38,42,48,50,59,60,62-64,66]$. The types of EFA tests used were principal component analysis (PCA) in 18 studies [17, 22, 24, 25, 27, 28, 31, 39, $41,43-45,49,51,57,58,65,67,68]$, maximum likelihood estimation (MLE) in $6[16,17,22,24,40,41,53]$ and unreported in $2[30,52]$ (Table 2). The types of rotation used for EFA were orthogonal varimax in 8 studies [28, 39, 41, 43, 44, 46, 49, 52, 65], oblique direct oblimin in $8[16,17,22,24,25,51,53,61]$, oblique promax in 5 $[40,45,46,58,65]$, standardized geomin 1 [30], and unreported in $4[27,31,57,67]$. Few of the studies justified the type of extraction or rotation used. Seven studies reported using a Cattell's scree test to determine the number of factors to retain [16, 17, 44, 46, 58, 61, 65, 69]. Fifteen studies employed the Kaiser criterion of 


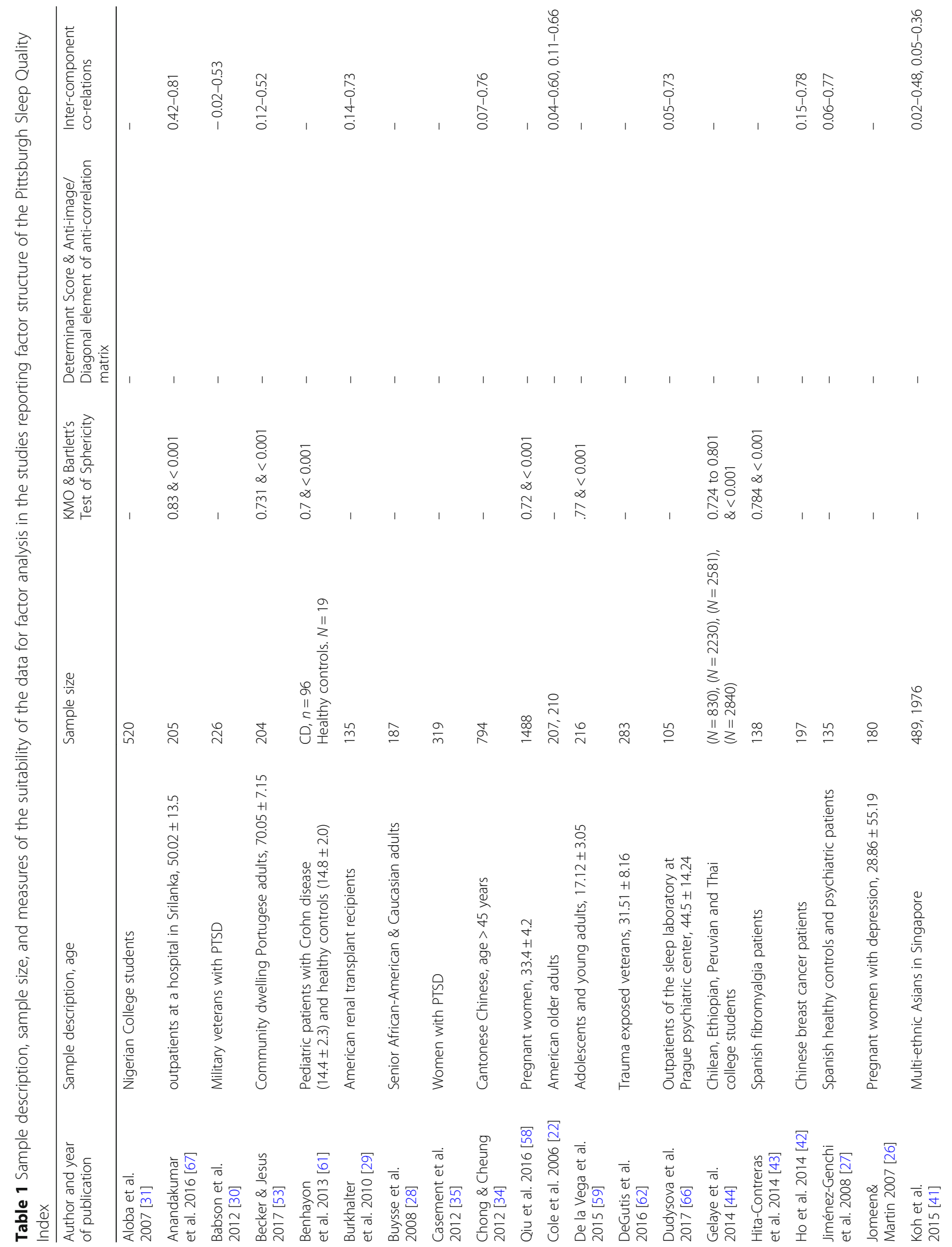




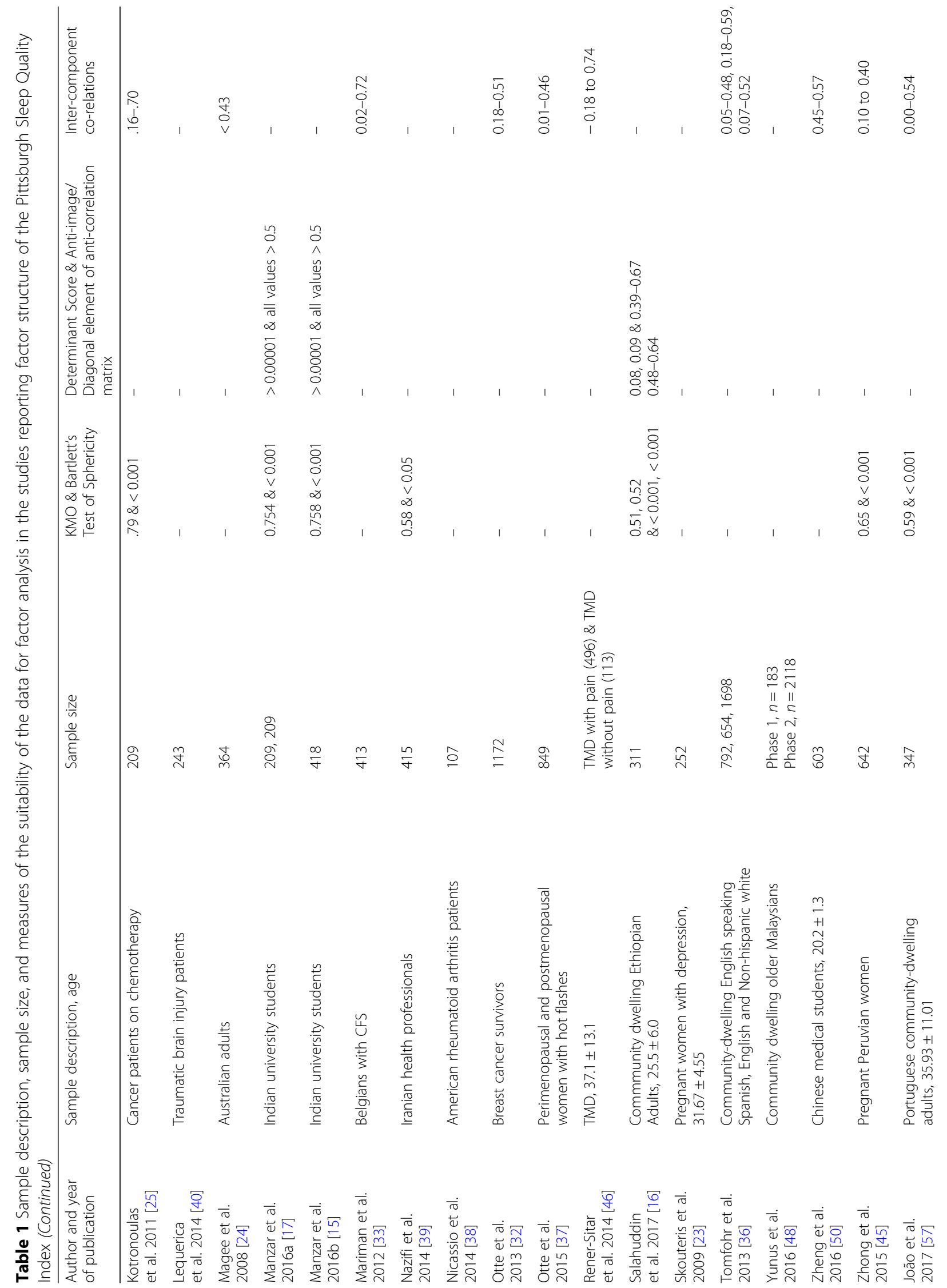




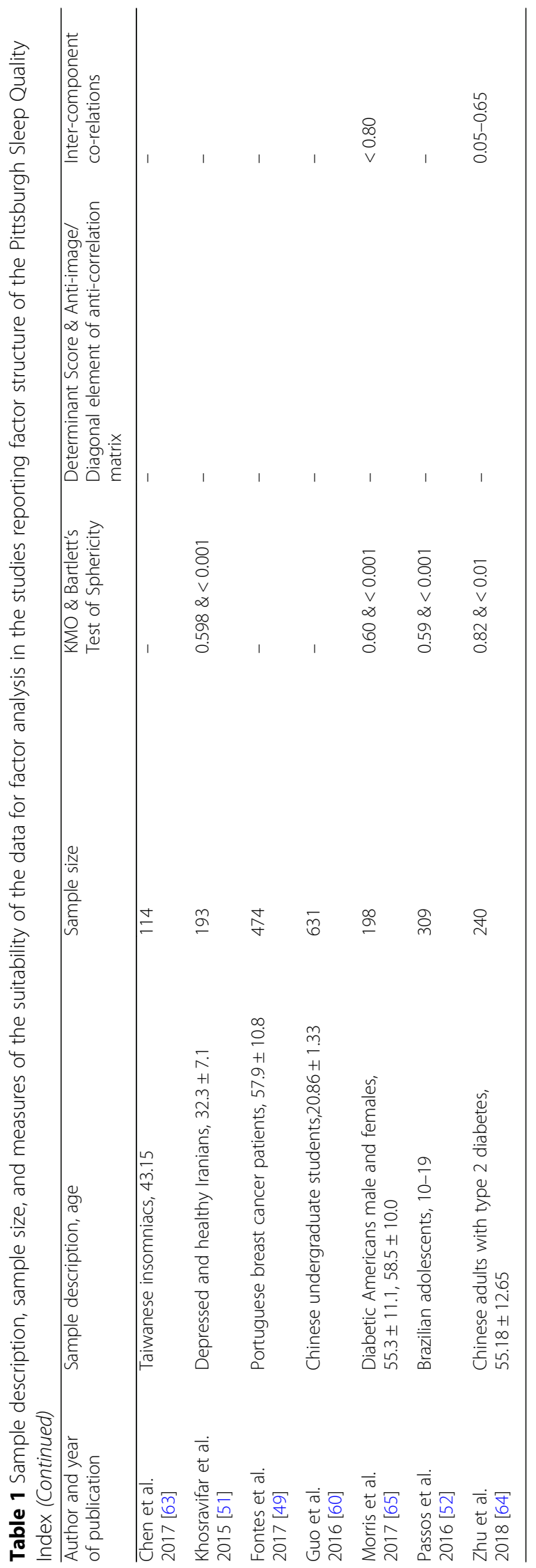




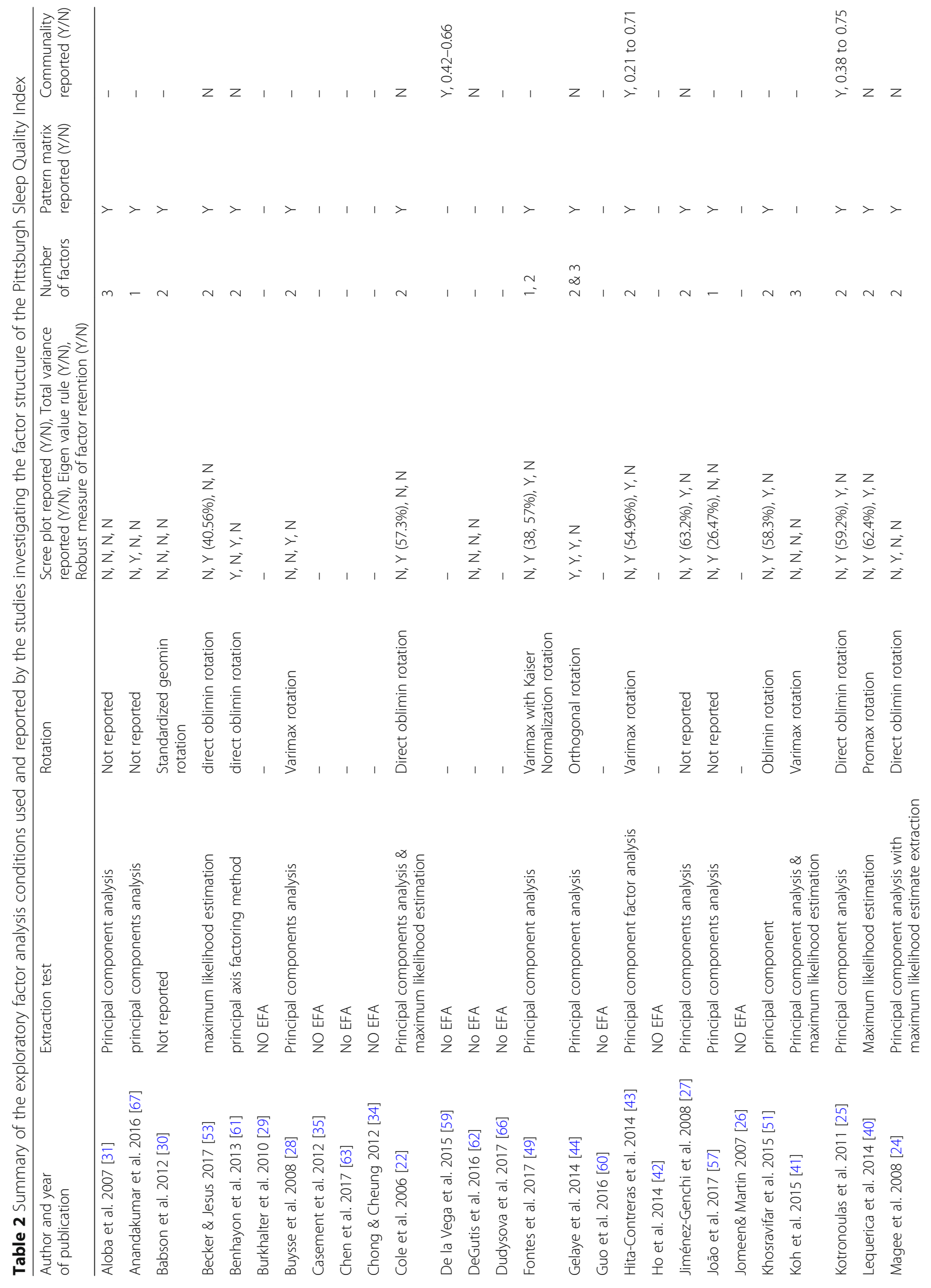




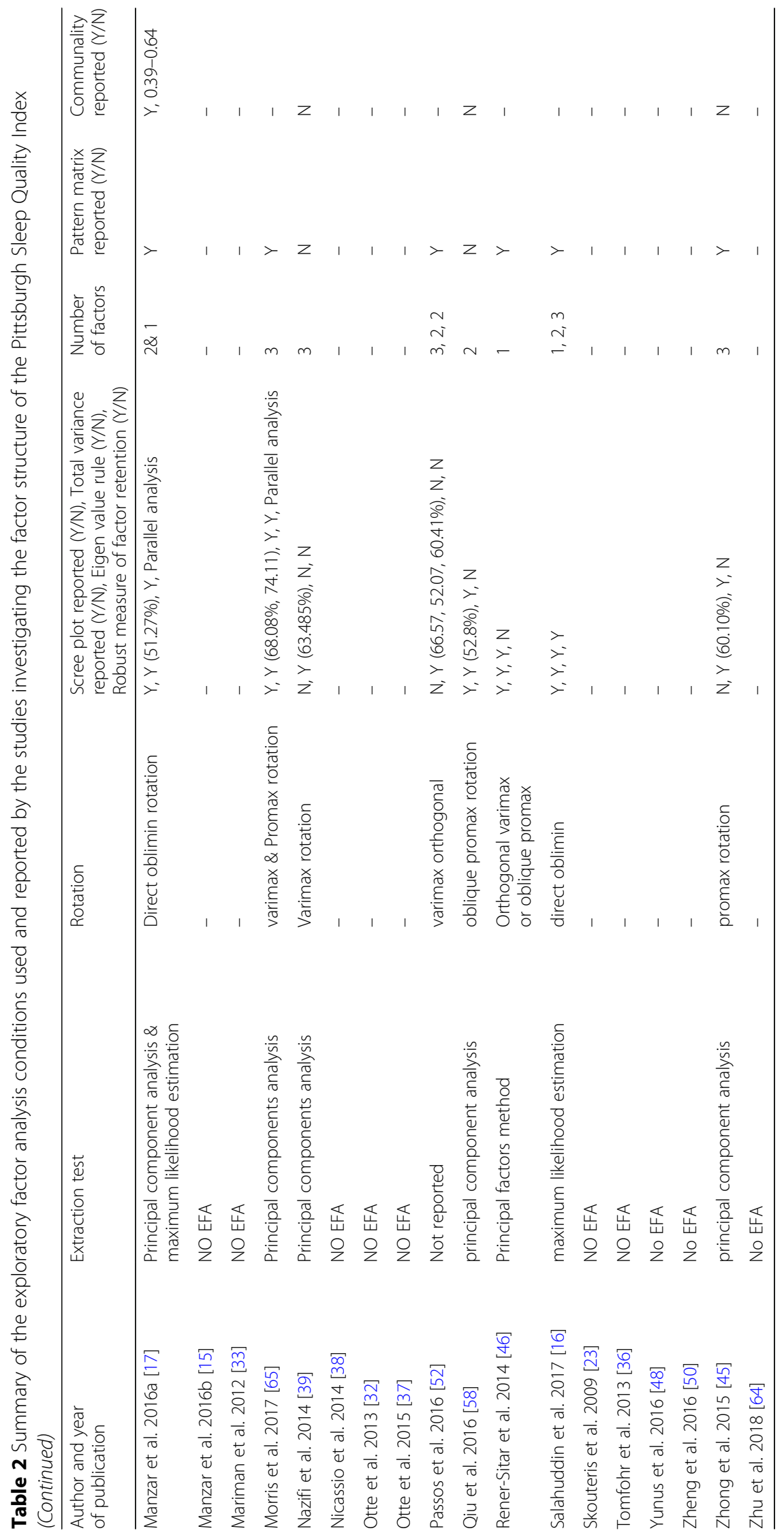




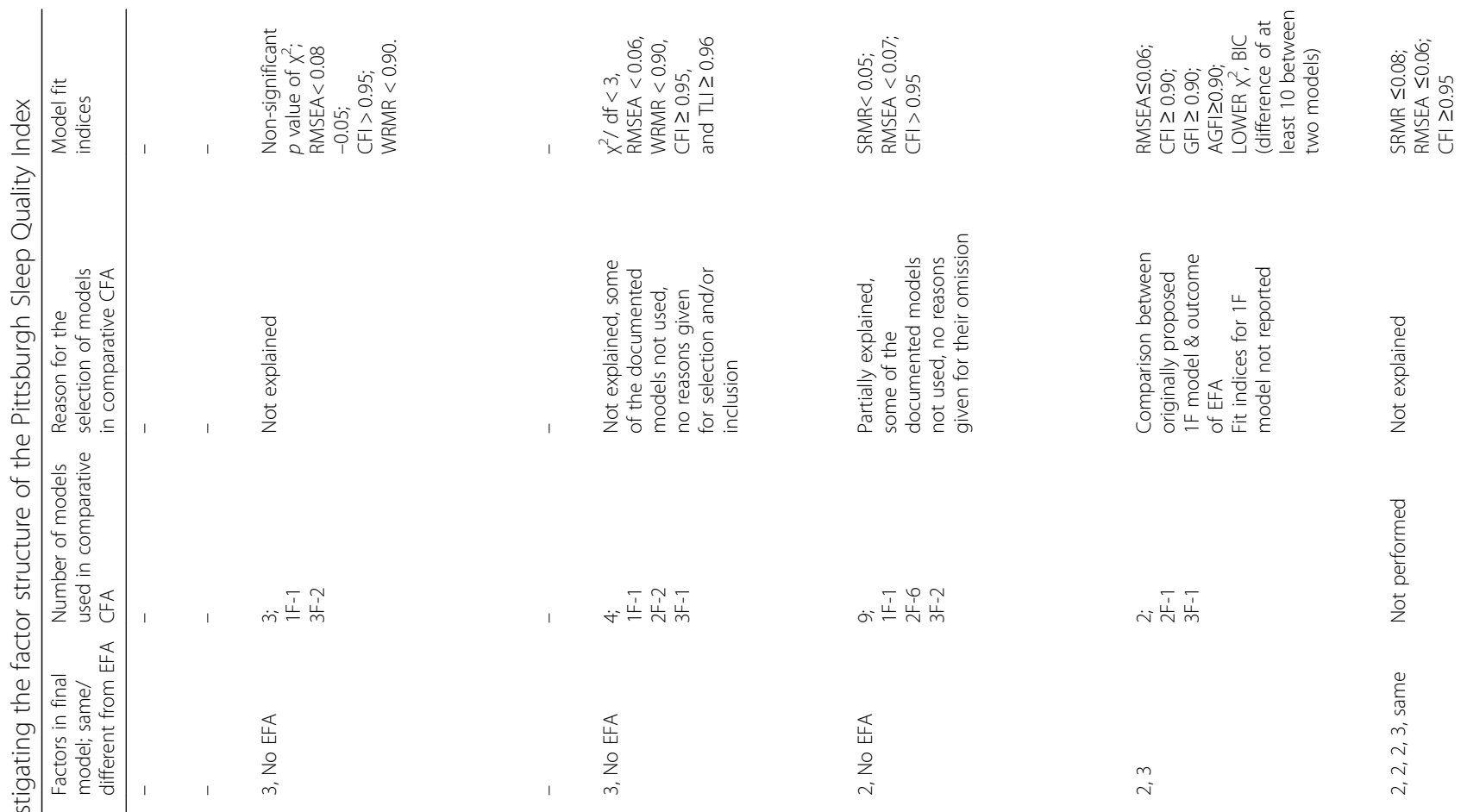

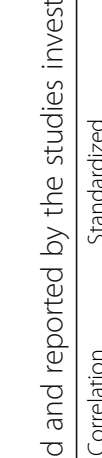




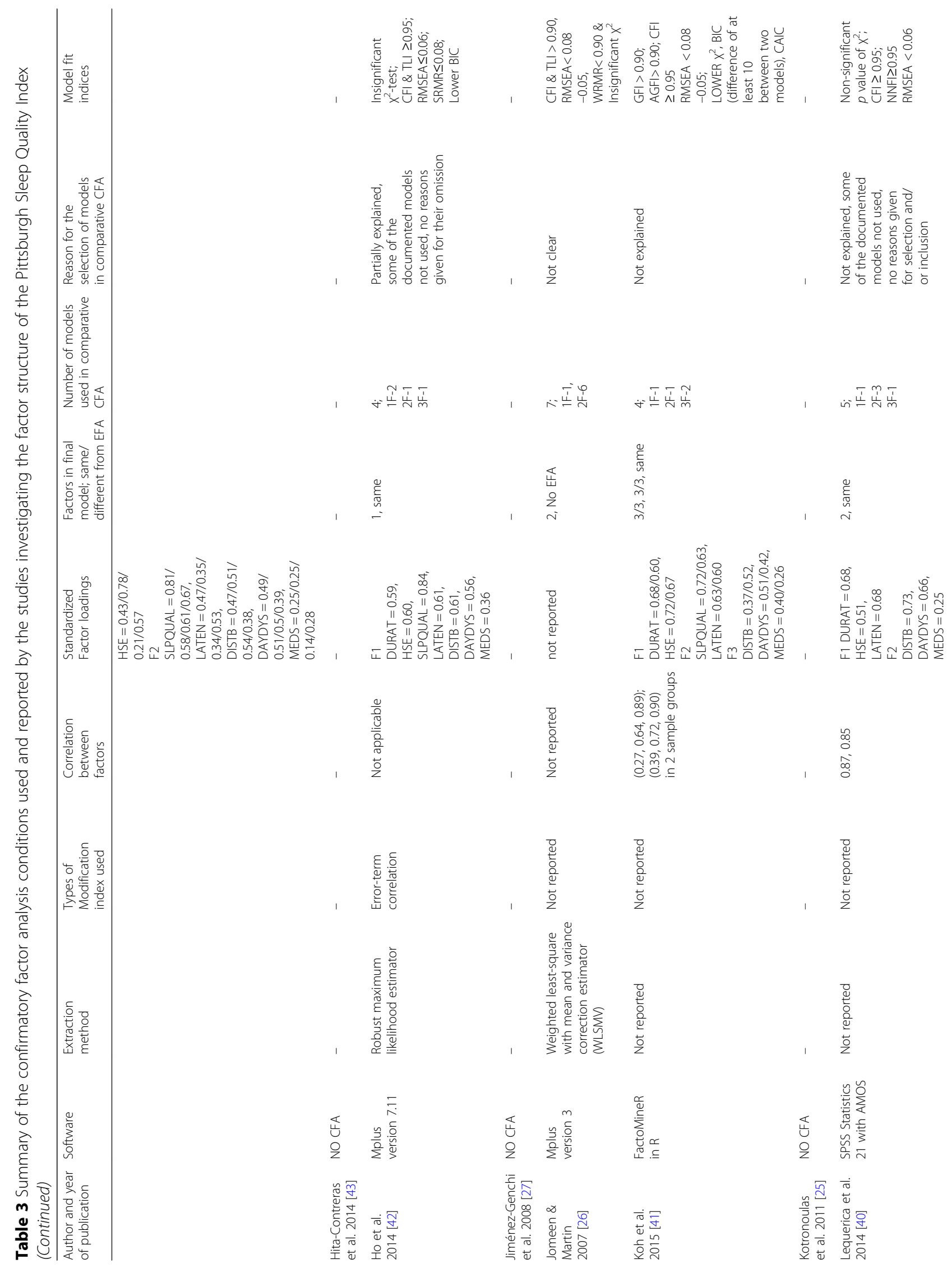




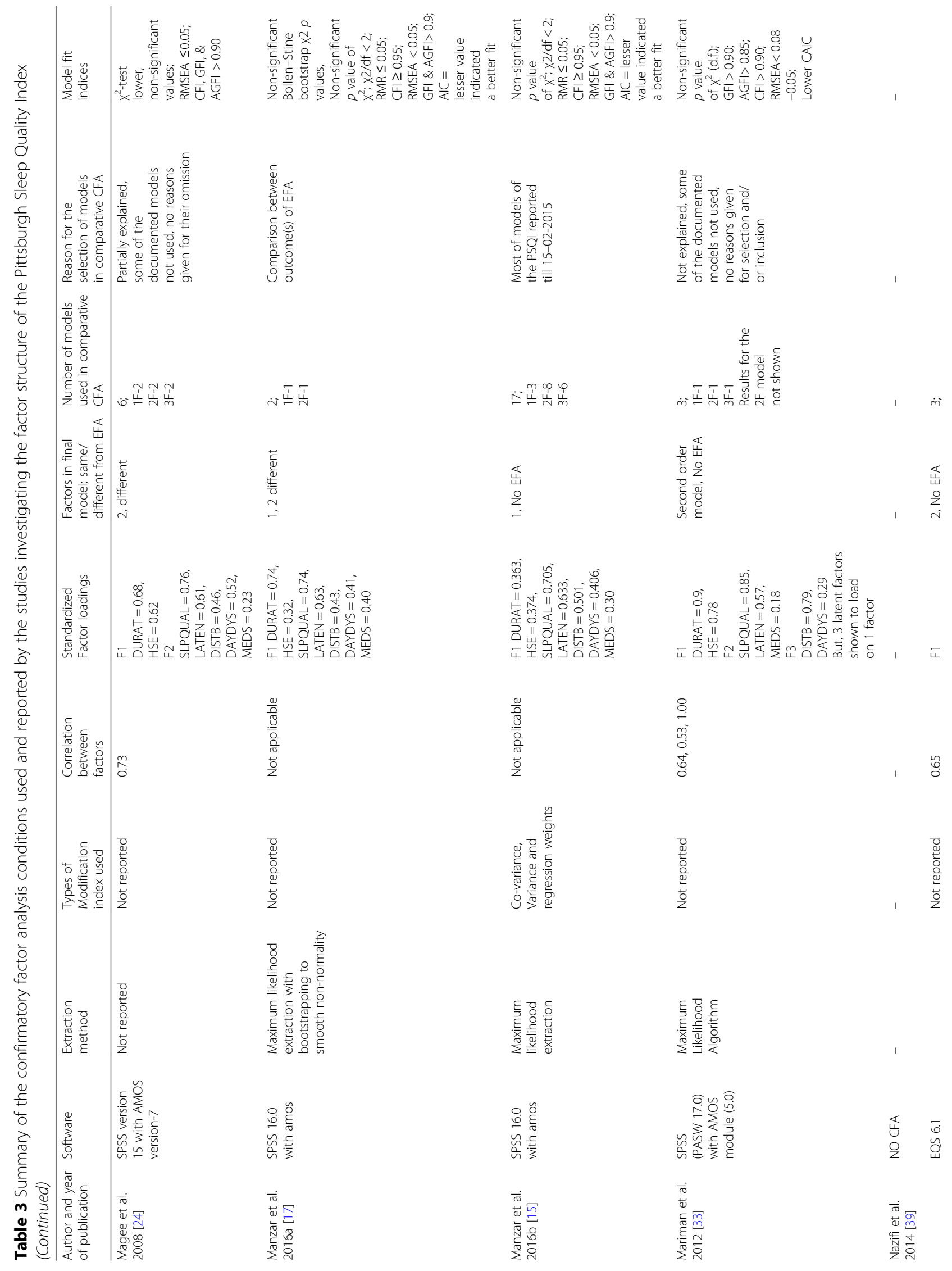




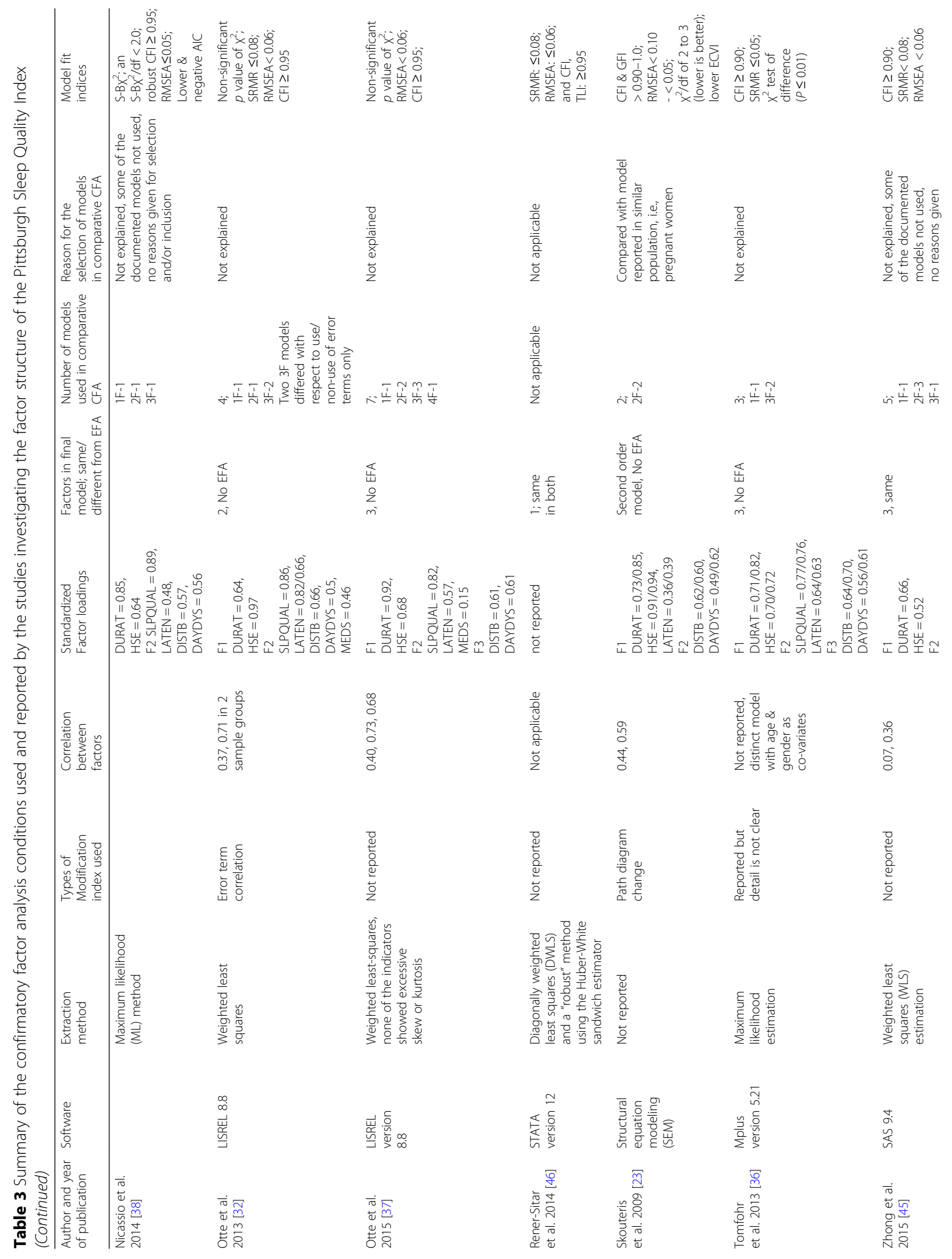




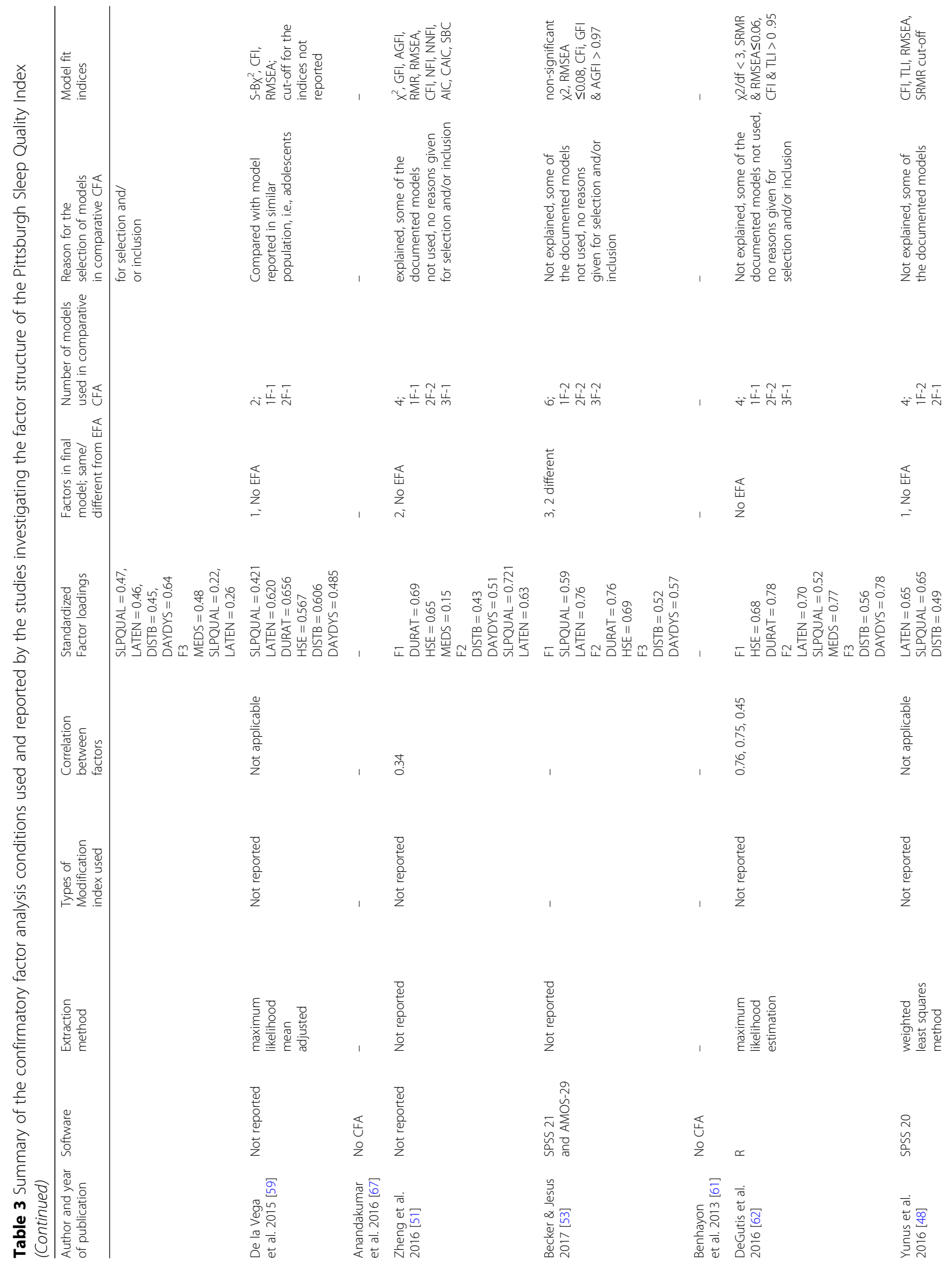




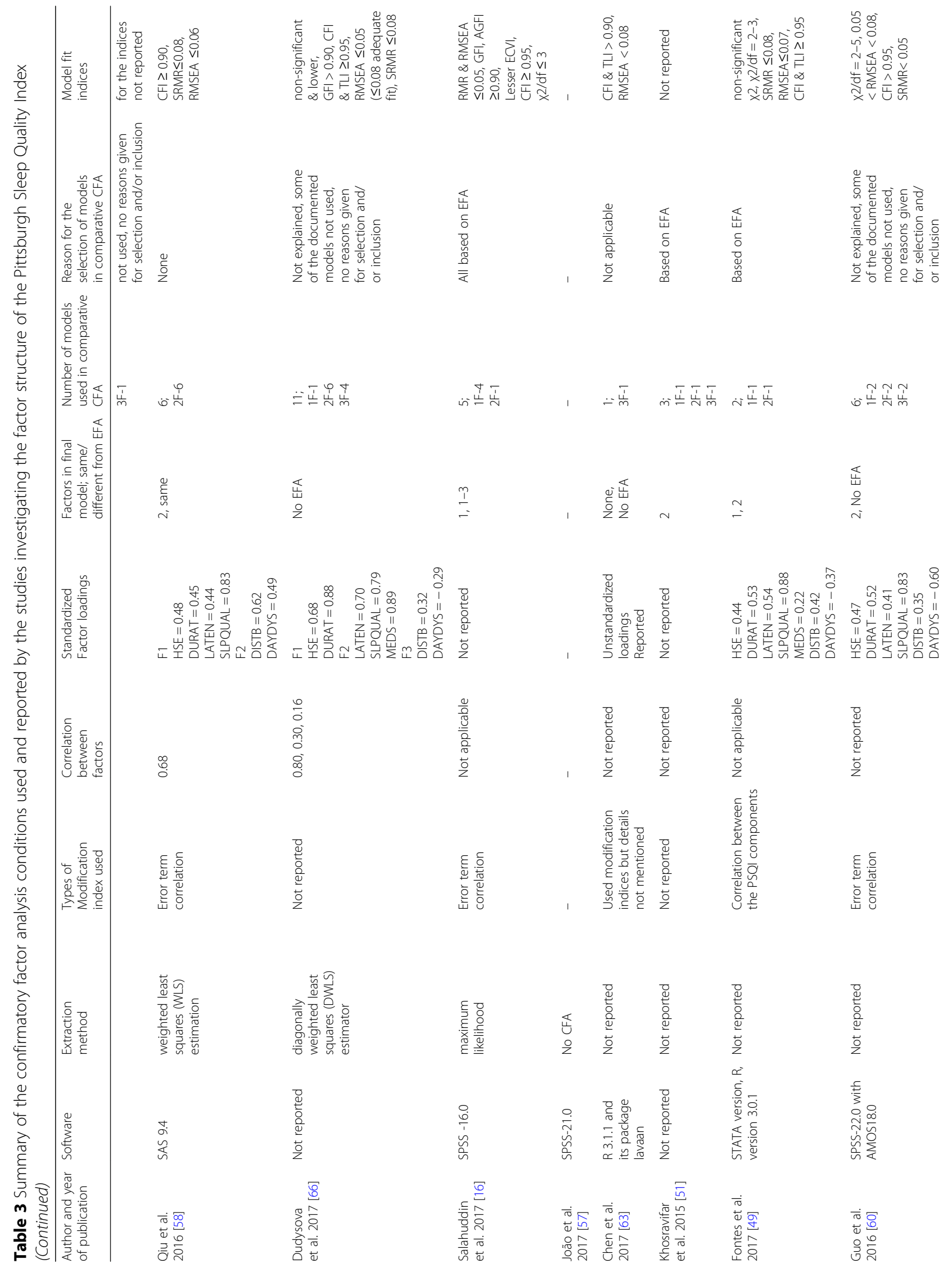




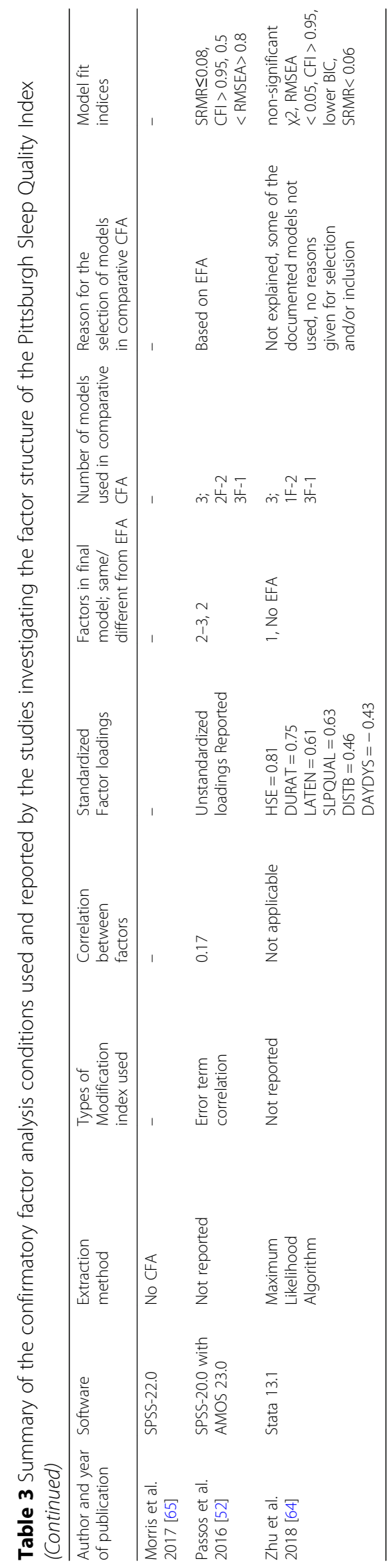


eigenvalue greater than one $[16,17,25,27,28,40,43-$ $46,49,51,58,61,65]$.

There is increasing consensus among statisticians that, parallel analysis and Velicer's minimum average partial (MAP) test, are better than to other procedures. This is because these methods usually give optimal solutions for the number of factors to retain [70]. However, only 4 studies used parallel analysis [16, 17, 49, 65, 71]. Fifteen studies used multiple criteria for factor retention $[16,17$, $25,27,40,43-46,49,51,52,58,61,65]$. The number of factors retained after EFA varied across articles. Five studies reported a 1-dimensional PSQI structure [16, 17, $46,52,67], 17$ reported a 2-dimensional structure [16, $17,22,24,25,27,28,30,40,43,44,49,51-53,58,61]$, and 8 reported a 3 -dimensional structure $[16,31,39,41$, $44,45,52,65]$. Twenty studies reported the cumulative percent of variance extracted $[16,17,22,25,27,39,40$, $43,45,49,51-53,57,58,65,67]$. Only 4 studies reported the value of communality retention criteria of items for factor analysis $[17,25,43,59]$.

\section{Confirmatory factor analysis}

As in the investigation of EFA, the overall finding for CFA was that a broad range of analytic techniques was used, all yielding a variety of inferred factor models. Eleven studies did not use CFA [25, 27, 28, 30, 31, 39, 43, 57, 61, 65, 67] (Table 3). Several different software programs were used for CFA: 6 studies used Mplus [26, 29, 34-36, 42], 12 used SPSS with Amos [15-17, 24, 33, 40, 48, 52, 53, 57, 60, 65], 4 used STATA [44, 46, 49, 64] and 2 each used LISREL [32, 37], and SAS [45 [58]], 1 each used FactoMineR [41], EQS [38], and SEM [23]. Five studies did not report which software program was used $[22,50,51,59,66]$. Thirteen studies did not report the method of extraction [23, 24, 29, 34, 40, 41, 49-53, 60, 63]. Nine studies used weighted least squares methods [26, 32, 35, 37, 45, 46, 48, 58, 66], 8 employed MLE $[15,16,33,36,38,44,59,62], 2$ used MLE with bootstrapping for smoothing multivariate non-normality [17, 22], and 1 used robust MLE [42] (Table 3). Most of the studies did not use a modification index $[17,24,26,33-35,37,38,40$, 41, 44-46]. Twelve studies reported the result of the suggestions of the modification indices, 2 used path diagram change [23, 29], 6 used correlations between error terms [15, $16,32,42,58,60], 1$ used path diagram change with Lagrange modifiers [22], and 2 did not provide details [36, 63] (Table 3). The reported correlation values between the factors of the final CFA models varied from 0.07 to 1.0. Some studies failed to report correlation values between the factors [26, 36] (Table 3).

Eight studies found that a 3-factor model best explained the data $[29,35-37,41,45,52,53]$, Thirteen reported a 2-factor model [22, 24, 26, 32, 34, 38, 40, 50$52,58,60]$, and 9 reported a 1 -factor model [15-17, 42, $46,48,49,59,64]$. One study reported both 2 -factor and 3-factor models, but in separate sample populations [44] (Table 3). Two studies reported second-order models; i. e., 2 or 3 first-order latent factors loaded on a higherorder factor [23, 33] (Table 3). Seven studies found the same PSQI structure with both EFA and CFA [40-42, 44-46, 58], while 3 derived different models from EFA and CFA [17, 22, 24] (Table 3). The medicine component of the PSQI was removed from the final models in some studies [23, 36, 38], while sleep quality component of the PSQI was not reported in the final model by 2 studies $[23,40]$ (Table 3 ). Two studies reported finding a 2-factor model with just 5 PSQI components [16, 23], while 1 study reported a model with only three PSQI components [48] (Table 3). Three studies reported final models with cross-loads [29, 45, 63]. Two studies reported non-standardized factor loadings, while 2 studies did not report the factor loadings (Table 3) [26, 29, 46, 63]. The studies showed little variation in number, types, and limit values of the fit indices used.

\section{Discussion}

Sample description, sample size, and measures of the suitability of the data for factor analysis

The gradual development of a heterogeneous multiple factor structure of the PSQI has often been defended by the complexities of sleep problems among diverse samples. However, there is no consensus about this assertion that complexities of sleep problems in diverse samples must result in multiple factor structure [15]. Moreover, this speculative presumption conveniently ignores to explain why the measured variables, i.e. individual items of the PSQI and the PSQI component scores cannot account for this complexity.

The appropriate sample size for factor analysis is a frequently debated topic among statisticians. There are disparate guidelines [72-74]. There are also different opinions on such issues as sample to variable ratio ( $\mathrm{N}: \mathrm{p}$ ratio) criteria [72, 75], the factorability of the correlation matrix [76, 77], use of the KMO/Bartlett's Test of Sphericity $[76,78]$, and use of the determinant of the matrix and anti-image or diagonal element of the anticorrelation matrix [72]. The suitable data for factor analysis and replicable factor extraction may require large samples and the satisfaction of a number of conditions as determined by such measures as the KMO, Bartlett's test, the determinant of the matrix, the anti-image of the anti-correlation matrix, and inter-component correlations [79]. A non-zero determinant of the matrix indicates the absence of multi-collinearity, meaning that linear combinations of items can form factors [80, 81].

The non-reporting of these conditions by the majority (29 out of 45) of studies may create doubt about the applicability of the reported factor structures, even in the study populations. Three studies reported all but 
inter-component correlations) [15-17], while 7 reported $\mathrm{KMO}$, Bartlett's test and inter-component correlations (Table 1) [25, 39, 43-45, 53, 57, 64, 65, 67]. The conclusions about dimensionality of the PSQI by some of these studies are limited by non-reporting of CFA (Table 3) $[25,39,43]$, or non-reporting of EFA [15]. However, reporting of multiple sample size suitability indices by these studies indicate suitability of their data for factor analysis $[15,17,25,39,43-45]$.

\section{Exploratory factor analysis}

The non-reporting of EFA results is fundamentally contrary to recommended norms for factor analysis, a deficiency that is particularly important considering the debate about the number and patterns of common factors for the PSQI $[4,15,17,82]$. Although the choice of extraction types for performing EFA is much-debated, though some prefer the use of principal axes for initial solutions [72]. The choice of the extraction method (principal axis or principal factors) may depend on the underlying data and the assumptions [60]. Many studies failed to report the final extraction method used in the EFA (Table 2). Four studies reported using MLE for the final extraction [17, 22, 24, 41], but 3 of these did not report the normality and/or skewness of the distribution of data being analyzed [22, 24, 41]. The extracted factors' applicability seems unclear because MLE entails multivariate normality [83]. Two studies reported using the principal factors method and principal component factor analysis, the authors might have meant principal axis method and PCA, respectively $[43,46]$. Under these circumstances, it is unsurprising that most of the studies did not explain the types of extraction used, plus most of the studies did not explain the choice of rotation.

Factor rotation increases interpretability by optimizing a simple structure with a distinct cluster of interrelated variables loading on the least number of latent variables [80]. Oblique rotations are better suited to accounting for the inter-relationships in the clinical data. They can be used even when the factors are not significantly correlated [81]. However, the use of rotation methods in the PSQI factor analysis studies is inconsistent. Of the studies reporting rotation methods, similar numbers used orthogonal and oblique rotations (Table 2). Some of the studies using orthogonal rotation did report the correlation value of the extracted factors [28, 30, 41, 43, 44]. The reported factor correlations were in the range of 0 . 1-0.9 [39, 41, 44]. Therefore, the factor correlation values of the various PSQI models do not seem to support the choice of orthogonal rotation methods.

There are many criteria for determining the number of factors to be retained from EFA. These include the Cattell's Scree test, Kaiser Criterion of Eigenvalue greater than one, the percentage of cumulative variance explained, and robust measures such as Horn's Parallel analysis, the Broken-Stick (B-S) criterion, and the minimum average partial (MAP) test [72, 84]. These tests have many limitations, and more so for the first three tests mentioned earlier. Therefore, the consensus opinion is to employ multiple criteria [72, 84]. It is perhaps concerning that only approximately one-third of the PSQI factor analysis studies used multiple criteria, and none used multiple robust measures (Table 2) [84]. The $\mathrm{B}-\mathrm{S}$ criterion and MAP test were not used by any of the studies exploring the PSQI's factor structure. The communality accounts for the variance of the common factors. Factor analysis aims to explain variance through common factors. Therefore communalities less than 0 . 2 are removed [80]. However, communality criteria were frequently under-reported in the studies investigating the PSQI's factor structure (Table 2). These inconsistencies and discrepancies might explain the variation in the number of factors retained after EFA (Table 2) $[4,15,17]$.

\section{Confirmatory factor analysis}

For finding prospective models and validation of the dimensionality of a questionnaire tool in discrete populations, it is recommended that factor analysis studies use both EFA and CFA [80]. More than $68 \%$ of the studies investigating the PSQI's factor structure employed either EFA or CFA. Some of the PSQI models are based only on EFA $[25,27,28,31,39,43]$, while some are based only on CFA [15, 23, 26, 29, 32, 34-36, 38, 42], neither of which is the recommended practice for performing factor analysis [85].

Another issue is the influence of user software. The software packages used to perform CFA (LISREL, Mplus, SAS, STATA, Amos, and EQS) differ with regard to estimation; path diagrams; availability of standard errors for standardized estimates, factor covariance, and factor correlations; availability of modification indices; and ability to handle different types (i.e., continuous and categorical) of measured and latent variables [68]. However, the fact that studies investigating the PSQI's factor structure used different software for CFA should not affect the results, as there are only slight differences in the statistics reported by the various programs, but the solutions are comparable [15]. LISREL, Mplus, SAS and STATA can handle the PSQI component scores, which are ordered as categorical variables, using diagonally weighted least squares estimation methods. Amos cannot accurately estimate models because it treats the PSQI component scores as measured variables. This is especially true if the PSQI component scores' distributions are characterized by skewness and kurtosis [17, 68]. However, Amos allows model estimation using MLE with bootstrapping to smooth non-normality with standardized estimates of 
factor loading [86]. Non-reporting of distribution characteristics is a common problem with the PSQI factor analysis studies. Further, some studies using SPSS with Amos did not describe their extraction and bootstrapping methods $[24,40]$. More than a quarter of the studies (i.e.13 out of 34 studies that used CFA) failed to report their extraction methods (Table 3). It is therefore difficult to reach a conclusion about the applicability of these studies' results. Modification indices should be used discretely to avoid over-capitalization on sample specific variations. It may be better to validate the modification index incorporated models on unrelated samples [87]. Few studies reported using the modification index, and they did not explain the choice of the type of modification index [23, 29, 32, 36, 42].

Inter-factor correlation of 0.85 and above arises from multicollinearity and indicate poor discriminant validity [88]. The reported correlation coefficients between CFA model factors were as high as $0.89,0.9$, and $1.0[33,41]$. This is technically undesirable because correlation coefficients greater than 0.9 suggest that the 2 correlated factors might not be practically distinct. Instead, the items loading on them might load on a common factor [17]. Jomeen and Martin [26] did not report inter-factor correlations in their final model. Moreover, they failed to report the factor loadings (Table 3). It is therefore difficult to reach a conclusion about their model's parsimony.

Low loadings for some of the PSQI components' scores (i.e., medicine component and sleep quality component) in some studies might reflect a reduced sensitivity of the questionnaire items measuring them $[23,36$, $38,40]$. Tomfohr et al. [36] reported only the intercomponent correlations as a sample size adequacy measure, did not use EFA, and did not provide details regarding the modification index. Among all the studies, Dudysova et al. [66] had the smallest sample size at 105. They did not report their EFA findings, nor did they provide information regarding suitability of the data for factor analysis, such as the KMO test, Bartlett's test, determinant score, nor anti-image matrix. Similarly, Skouteris et al. [23] did not report their findings regarding EFA or sample size adequacy measures. They also did not report the CFA extraction method. Lequerica et al. [40] did not report any sample size measures or the CFA extraction method. The study used Amos without reporting normality conditions or bootstrapping.

Methodological discrepancies between these studies might have affected their results and the reliability of their findings. The model fit indices were streamlined with regard to number, types, and limit values (Table 3 ). Almost all the reviewed studies used multiclass model fits, which is consistent with generally accepted guidelines for factor analysis [89]. Gelaye et al. reported using 4 model fit indices in their study but mentioned the cut- off criteria of only 3. A model fit was presented for a 2factor solution, though the EFA supported a 3-factor model $[17,44]$. It is also concerning that in almost all the studies, the basic parsimony requirements for factor analysis were not upheld [15, 17]. It is worth noting that the recommended practice for factor analysis gives preference to parsimonious models over multidimensional models if differences are irreconcilable [47]. Therefore, the non-application of parsimony, together withother procedural discrepancies, has made it difficult to endorse the applicability of the various PSQI factor structures, even in similar samples.

\section{Practice points for future}

- The studies investigating factor analysis of a questionnaire should employ both EFA and CFA.

- The reporting of details of sample suitability for factor analysis is preferable. This gives supporting evidence about distribution, levels of multicollinearity, singularity, and shared variance among measured variables.

- The details of EFA like extraction methods, rotation and factor retention should be reported along with their justification.

- The reporting of CFA like extraction methods and modification indices is preferable along with their justification.

- It is preferable to employ multiple goodness of fit indices from different categories.

\section{Limitations}

This review has some limitations. We did not perform a meta-analysis, but the discrepancies made that almost impractical. The studies' methodological qualities were not assessed, but such approaches have their own demerits [1]. We mostly reviewed articles published in the English language; with only 2 non-English articles included after their authors approved/provided a translation of the factor analysis sections [27]. Some authors did not respond to the queries regarding details of the factor analysis in their study. The authors of the other included articles were not contacted. Model fit indices were not discussed in detail because the studies were methodologically sound in this regard. Interested readers are referred Cheung and Rensvold [90].

\section{Conclusion}

The results of this review do not permit an optimistic conclusion regarding the applicability of factor analysis studies on this widely used questionnaire. The generalizations from the majority are severely limited by issues including non-application of parsimony, non-use of EFA or non-reporting of relevant details, and non-use of CFA 
or non-reporting of relevant details. The generalizations from studies using small size may be difficult. Furthermore, under- or non-reporting of sample adequacy measures "and" non-reporting of relevant details make understanding the diversity of factor structures difficult to interpret. In summary, the factor analysis may not be replicable across different methodologies. The structured categorical data of the PSQI may be sensitive to the specific model (method of extraction) being applied.

Therefore, the applicability of the various PSQI factor structures even in related samples seems doubtful.

\section{Acknowledgements}

We are grateful to the Mizan-Tepi University for providing the running cost of the project.

\section{Authors' contributions}

MDM: Concept development and study design, analysis and interpretation, manuscript preparation, critical revision of the manuscript, and approved the final version of the manuscript. AS: Interpretation, manuscript preparation, critical revision of the manuscript, and approved the final version of the manuscript. UAH: Interpretation, manuscript preparation, critical revision of the manuscript, and approved the final version of the manuscript. DWS: Interpretation, manuscript preparation, critical revision of the manuscript, and approved the final version of the manuscript. SRP: Interpretation, manuscript preparation, critical revision of the manuscript, and approved the final version of the manuscript. AM: Interpretation, manuscript preparation, critical revision of the manuscript, and approved the final version of the manuscript. DLS: Interpretation, manuscript preparation, critical revision of the manuscript, and approved the final version of the manuscript. All authors read and approved the final manuscript.

\section{Ethics approval and consent to participate}

The study was approved by the Human Institutional Ethics Committee of Mizan-Tepi University.

\section{Competing interests}

The authors declare that they have no competing interests.

\section{Publisher's Note}

Springer Nature remains neutral with regard to jurisdictional claims in published maps and institutional affiliations.

\begin{abstract}
Author details
'Department of Nursing, College of Applied Medical Sciences, Majmaah University, Al Majmaah, Kingdom of Saudi Arabia. ${ }^{2}$ Department of Biomedical Sciences, College of Medicine and Health Sciences, Mizan-Tepi University (Mizan Campus), Mizan-Aman, Ethiopia. ${ }^{3}$ The University Sleep Disorders Center, Department of Medicine, College of Medicine, King Saud University, Riyadh, Saudi Arabia. ${ }^{4}$ The National Plan for Science and Technology, King Saud University, Riyadh, Saudi Arabia. ${ }^{5}$ Department of Physiotherapy, Fatima College of Health Sciences, Al Mafraq, Abu Dhabi City, United Arab Emirates. ${ }^{6}$ Toronto, Canada. ${ }^{7}$ Sleep and Fatigue Institute, University of Calgary, Calgary, AB, Canada. ${ }^{8}$ Department of Psychiatry and Behavioral Neurosciences, McMaster University, Hamilton, ON, Canada. ${ }^{9}$ Department of Psychiatry, University of Toronto, Toronto, ON, Canada.
\end{abstract}

Received: 25 October 2017 Accepted: 29 April 2018

Published online: 09 May 2018

\section{References}

1. Ohayon MM. Epidemiological overview of sleep disorders in the general population. Sleep Med Res. 2011:2:1-9.

2. Attarian HP. Epidemiology of sleep disorders in women. In: Attarian HP, Viola-Saltzman M, editors. Sleep disorders in women: a guide to practical management. New York: Springer Science+Business Media; 2013.
3. de Souza Lopes C, Robaina JR, Rotenberg L. Epidemiology of insomnia: prevalence and risk factors. In: Sahoo S, editor. In Can't sleep? Issues of being an insomniac: In Tech; Shanghai. 2012. p. 1-21.

4. Mollayeva T, Thurairajah P, Burton K, Mollayeva S, Shapiro CM, Colantonio A. The Pittsburgh sleep quality index as a screening tool for sleep dysfunction in clinical and non-clinical samples: a systematic review and meta-analysis. Sleep Med Rev. 2016;25:52-73.

5. Manzar MD, Moiz JA, Zannat W, Spence DW, Pandi-Perumal SR, Hussain ME. Validity of the Pittsburgh sleep quality index in Indian university students. Oman Med J. 2015;30:193-202.

6. Udwadia ZF, Doshi AV, Lonkar SG, Singh Cl. Prevalence of sleep-disordered breathing and sleep apnea in middle-aged urban Indian men. Am J Respir Crit Care Med. 2004;169:168-73.

7. Sweileh WM, Ali IA, Sawalha AF, Abu-Taha AS, Zyoud SH, Al-Jabi SW. Sleep habits and sleep problems among Palestinian students. Child Adolesc Psychiatry Ment Health. 2011;5:25.

8. Leger D, Bayon V, Ohayon MM, Philip P, Ement P, Metlaine A, Chennaoui M, Faraut B. Insomnia and accidents: cross-sectional study (EQUINOX) on sleeprelated home, work and car accidents in 5293 subjects with insomnia from 10 countries. J Sleep Res. 2014;23:143-52.

9. Shekleton JA, Flynn-Evans EE, Miller B, Epstein LJ, Kirsch D, Brogna LA, Burke LM, Bremer E, Murray JM, Gehrman P, et al. Neurobehavioral performance impairment in insomnia: relationships with self-reported sleep and daytime functioning. Sleep. 2014;37:107-16.

10. Fortier-Brochu E, Beaulieu-Bonneau S, Ivers H, Morin CM. Insomnia and daytime cognitive performance: a meta-analysis. Sleep Med Rev. 2012;16: 83-94.

11. Guallar-Castillon P, Bayan-Bravo A, Leon-Munoz LM, Balboa-Castillo T, LopezGarcia E, Gutierrez-Fisac JL, Rodriguez-Artalejo F. The association of major patterns of physical activity, sedentary behavior and sleep with healthrelated quality of life: a cohort study. Prev Med. 2014;67:248-54.

12. Buysse DJ, Reynolds CF 3rd, Monk TH, Berman SR, Kupfer DJ. The Pittsburgh sleep quality index: a new instrument for psychiatric practice and research. Psychiatry Res. 1989;28:193-213.

13. Bassetti C, Dijk D, Dogas Z, Levy P. The future of sleep research and sleep medicine in Europe: a need for academic multidisciplinary sleep Centres. In: European Sleep Research Society 1972-2012. 2012.

14. Manzar MD, Zannat W, Hussain ME. Sleep and physiological systems: a functional perspective. Biol Rhythm Res. 2015;46:195-206.

15. Manzar MD, Zannat W, Moiz JA, Spence DW, Pandi-Perumal SR, Bahammam AS. Factor scoring models of the Pittsburgh sleep quality index: a comparative confirmatory factor analysis. Biol Rhythm Res. 2016; 47:851-64.

16. Salahuddin M, Maru TT, Kumalo A, Pandi-Perumal SR, Bahammam AS, Manzar MD. Validation of the Pittsburgh sleep quality index in community dwelling Ethiopian adults. Health Qual Life Outcomes. 2017;15:58.

17. Manzar MD, Zannat W, Hussain ME, Pandi-Perumal SR, Bahammam AS, Barakat D, Ojike NI, Olaish A, Spence DW. Dimensionality of the Pittsburgh sleep quality index in the collegiate young adults. Spring. 2016;5:1550

18. Child D. The essentials of factor analysis. New York: Bloomsbury Academic; 2006.

19. Harman HH. Modern factor analysis. Chicago: University of Chicago Press; 1976.

20. Bartholomew DJ, Knott M, Moustaki I. Latent variable models and factor analysis: a unified approach. West Sussex: Wiley; 2011.

21. McDonald RP. Factor analysis and related methods. New York: Psychology press; 2014.

22. Cole JC, Motivala SJ, Buysse DJ, Oxman MN, Levin MJ, Irwin MR. Validation of a 3-factor scoring model for the Pittsburgh sleep quality index in older adults. Sleep. 2006;29:112-6.

23. Skouteris H, Wertheim EH, Germano C, Paxton SJ, Milgrom J. Assessing sleep during pregnancy: a study across two time points examining the Pittsburgh sleep quality index and associations with depressive symptoms. Womens Health Issues. 2009;19:45-51.

24. Magee CA, Caputi P, Iverson DC, Huang XF. An investigation of the dimensionality of the Pittsburgh sleep quality index in Australian adults. Sleep Biol Rhythms. 2008;6:222-27.

25. Kotronoulas GC, Papadopoulou CN, Papapetrou A, Patiraki E. Psychometric evaluation and feasibility of the Greek Pittsburgh sleep quality index (GRPSQI) in patients with cancer receiving chemotherapy. Support Care Cancer. 2011;19:1831-40.

26. Jomeen J, Martin CR. Assessment and relationship of sleep quality to depression in early pregnancy. J Reprod Infant Psychol. 2007;25:87-99. 
27. Jimenez-Genchi A, Monteverde-Maldonado E, Nenclares-Portocarrero A, Esquivel-Adame G, de la Vega-Pacheco A. Reliability and factorial analysis of the Spanish version of the Pittsburg sleep quality index among psychiatric patients. Gac Med Mex. 2008;144:491-6.

28. Buysse DJ, Hall ML, Strollo PJ, Kamarck TW, Owens J, Lee L, Reis SE, Matthews KA. Relationships between the Pittsburgh sleep quality index (PSQI), Epworth sleepiness scale (ESS), and clinical/polysomnographic measures in a community sample. J Clin Sleep Med. 2008;4:563-71.

29. Burkhalter H, Sereika SM, Engberg S, Wirz-Justice A, Steiger J, De Geest S. Structure validity of the Pittsburgh sleep quality index in renal transplant recipients: a confirmatory factor analysis. Sleep Biol Rhythms. 2010;8:274-81.

30. Babson KA, Blonigen DM, Boden MT, Drescher KD, Bonn-Miller MO. Sleep quality among U.S. military veterans with PTSD: a factor analysis and structural model of symptoms. J Trauma Stress. 2012;25:665-74.

31. Aloba OO, Adewuya AO, Ola BA, Mapayi BM. Validity of the Pittsburgh sleep quality index (PSQI) among Nigerian university students. Sleep Med. 2007:8:266-70

32. Otte JL, Rand KL, Carpenter JS, Russell KM, Champion VL. Factor analysis of the Pittsburgh sleep quality index in breast cancer survivors. J Pain Symptom Manag. 2013;45:620-7.

33. Mariman A, Vogelaers D, Hanoulle I, Delesie L, Tobback E, Pevernagie D. Validation of the three-factor model of the PSQI in a large sample of chronic fatigue syndrome (CFS) patients. J Psychosom Res. 2012;72:111-3.

34. Chong AML, Cheung CK. Factor structure of a Cantonese-version Pittsburgh sleep quality index. Sleep Biol Rhythms. 2012;10:118-25.

35. Casement MD, Harrington KM, Miller MW, Resick PA. Associations between Pittsburgh sleep quality index factors and health outcomes in women with posttraumatic stress disorder. Sleep Med. 2012;13:752-8.

36. Tomfohr LM, Schweizer CA, Dimsdale JE, Loredo JS. Psychometric characteristics of the Pittsburgh sleep quality index in English speaking nonHispanic whites and English and Spanish speaking Hispanics of Mexican descent. J Clin Sleep Med. 2013;9:61-6.

37. Otte JL, Rand KL, Landis CA, Paudel ML, Newton KM, Woods N, Carpenter JS. Confirmatory factor analysis of the Pittsburgh sleep quality index in women with hot flashes. Menopause. 2015;22:1190-6.

38. Nicassio PM, Ormseth SR, Custodio MK, Olmstead R, Weisman MH, Irwin MR. Confirmatory factor analysis of the Pittsburgh sleep quality index in rheumatoid arthritis patients. Behav Sleep Med. 2014;12:1-12.

39. Nazifi M, Mokarami H. Psychometric properties of the Persian translation of Pittsburgh sleep quality. Health Scope. 2014;3:e15547.

40. Lequerica A, Chiaravalloti N, Cantor J, Dijkers M, Wright J, Kolakowsky-Hayner SA, Bushnick T, Hammond F, Bell K. The factor structure of the Pittsburgh sleep quality index in persons with traumatic brain injury. A NIDRR TBI model systems module study. NeuroRehabilitation. 2014;35:485-92.

41. Koh HW, Lim RB, Chia KS, Lim WY. The Pittsburgh sleep quality index in a multi-ethnic Asian population contains a three-factor structure. Sleep Breath. 2015:19:1147-54

42. Ho RT, Fong TC. Factor structure of the Chinese version of the Pittsburgh sleep quality index in breast cancer patients. Sleep Med. 2014;15:565-9.

43. Hita-Contreras F, Martinez-Lopez E, Latorre-Roman PA, Garrido F, Santos MA, Martinez-Amat A. Reliability and validity of the Spanish version of the Pittsburgh sleep quality index (PSQI) in patients with fibromyalgia. Rheumatol Int. 2014;34:929-36.

44. Gelaye B, Lohsoonthorn V, Lertmeharit S, Pensuksan WC, Sanchez SE, Lemma S, Berhane Y, Zhu X, Velez JC, Barbosa C, et al. Construct validity and factor structure of the Pittsburgh sleep quality index and Epworth sleepiness scale in a multi-national study of African, south east Asian and south American college students. PLoS One. 2014;9:e116383.

45. Zhong QY, Gelaye B, Sanchez SE, Williams MA. Psychometric properties of the Pittsburgh sleep quality index (PSQI) in a cohort of Peruvian pregnant women. J Clin Sleep Med. 2015;11:869-77.

46. Rener-Sitar K, John MT, Bandyopadhyay D, Howell MJ, Schiffman EL. Exploration of dimensionality and psychometric properties of the Pittsburgh sleep quality index in cases with temporomandibular disorders. Health Qual Life Outcomes. 2014;12:10.

47. Browne MW, Cudeck R. Alternative ways of assessing model fit. Sociol Methods Res. 1992;21:230-58

48. Yunus RM, Wazid SW, Hairi NN, Choo WY, Hairi FM, Sooryanarayana R, Ahmad SN, Razak IA, Peramalah D, Aziz SA. Association between elder abuse and poor sleep: a cross-sectional study among rural older Malaysians. PLoS One. 2017;12:e0180222.
49. Fontes F, Gonçalves M, Maia S, Pereira S, Severo M, Lunet N. Reliability and validity of the Pittsburgh sleep quality index in breast cancer patients. Support Care Cancer. 2017;25:3059-66.

50. Zheng B, Li M, Wang K, LV J. Analysis of the reliability and validity of the Chinese version of Pittsburgh sleep quality index among medical college students. Beijing Da Xue Xue Bao Yi Xue Ban. 2016:48:424-8.

51. Khosravifar S, Bandi MG, Alavi K, Javadi PHS. Evaluation of the psychometric properties of the Persian version of the Pittsburgh sleep quality index in depressed patients. Electron Physician. 2015;7:1644.

52. Passos MH, Silva HA, Pitangui AC, Oliveira VM, Lima AS, Araújo RC. Reliability and validity of the Brazilian version of the Pittsburgh sleep quality index in adolescents. J Pediatr. 2017:93:200-6.

53. Becker NB, de Neves Jesus S. Adaptation of a 3-factor model for the Pittsburgh sleep quality index in Portuguese older adults. Psychiatry Res. 2017;251:298-303.

54. Hancock P, Larner AJ. Diagnostic utility of the Pittsburgh sleep quality index in memory clinics. Int J Geriatr Psychiatry. 2009:24:1237-41.

55. Yurcheshen ME, Guttuso T Jr, McDermott M, Holloway RG, Perlis M. Effects of gabapentin on sleep in menopausal women with hot flashes as measured by a Pittsburgh sleep quality index factor scoring model. J Women's Health (Larchmt). 2009;18:1355-60.

56. Curcio G, Tempesta D, Scarlata S, Marzano C, Moroni F, Rossini PM, Ferrara M, De Gennaro L. Validity of the Italian version of the Pittsburgh sleep quality index (PSQI). Neurol Sci. 2013;34:511-9.

57. João KADR, Becker NB, de Neves Jesus S, Martins RIS. Validation of the Portuguese version of the Pittsburgh sleep quality index (PSQI-PT). Psychiatry Res. 2017;247:225-9.

58. Qiu C, Gelaye B, Zhong Q-Y, Enquobahrie DA, Frederick IO, Williams MA. Construct validity and factor structure of the Pittsburgh sleep quality index among pregnant women in a Pacific-northwest cohort. Sleep Breath. 2016; 20:293-301

59. de la Vega R, Tomé-Pires C, Solé E, Racine M, Castarlenas E, Jensen MP, Miró J. The Pittsburgh sleep quality index: validity and factor structure in young people. Psychol Assess. 2015;27:e22.

60. Guo S, Sun W, Liu C, Wu S. Structural validity of the Pittsburgh sleep quality index in Chinese undergraduate students. Front Psychol. 2016;7:1126.

61. Benhayon D, Youk A, McCarthy FN, Davis S, Keljo DJ, Bousvaros A, Fairclough D, Kupfer D, Buysse DJ, Szigethy EM. Characterization of relationships between sleep, inflammation, and psychiatric dysfunction in depressed youth with Crohn's disease. J Pediatr Gastroenterol Nutr. 2013;57:335.

62. DeGutis J, Chiu C, Thai M, Esterman M, Milberg W, McGlinchey R. Trauma sequelae are uniquely associated with components of self-reported sleep dysfunction in OEF/OIF/OND veterans. Behav Sleep Med. 2018;16:38-63.

63. Chen $\mathrm{P}-\mathrm{Y}$, Jan $\mathrm{Y}-\mathrm{W}$, Yang C-M. Are the insomnia severity index and Pittsburgh sleep quality index valid outcome measures for cognitive behavioral therapy for insomnia? Inquiry from the perspective of response shifts and longitudinal measurement invariance in their Chinese versions. Sleep Med. 2017;35:35-40.

64. Zhu B, Xie M, Park CG, Kapella MC. Adaptation of the Pittsburgh sleep quality index in Chinese adults with type 2 diabetes. J Chin Med Assoc. 2018;81:242-7.

65. Morris JL, Rohay J, Chasens ER. Sex differences in the psychometric properties of the Pittsburgh sleep quality index. J Women's Health. 2017;27: 278-82.

66. Dudysova D, Malá I, Mlada K, Saifutdinova E, Koprivova J, Sos P. Structural and construct validity of the Czech version of the Pittsburgh sleep quality index in chronic insomnia. Neuro Endocrinol Lett. 2017;38:67-73.

67. Anandakumar D, Dayabandara M, Ratnatunga S, Hanwella R, de Silva V. Validation of the Sinhala version of the Pittsburgh sleep quality index. Ceylon Med J. 2016;61;22-25.

68. Albright JJ, Park HM. Confirmatory factor analysis using Amos, LISREL, Mplus, SAS/STAT CALIS. Bloomington: Indiana University; 2009.

69. Cattell RB. The scree test for the number of factors. Multivar Behav Res. 1966:1:245-76.

70. O'connor BP. SPSS and SAS programs for determining the number of components using parallel analysis and Velicer's MAP test. Behav Res Methods Instrum Comput. 2000;32:396-402.

71. Horn JL. A rationale and test for the number of factors in factor analysis. Psychometrika. 1965;30:179-85.

72. Williams B, Onsman A, Brown T. Exploratory factor analysis: a five-step guide for novices. J Emerg Prim Health Care. 2010;8:990399. 
73. Comrey AL. A first course in factor analysis. New York: Academic Press; 1973.

74. Sapnas KG, Zeller RA. Minimizing sample size when using exploratory factor analysis for measurement. J Nurs Meas. 2002;10:135-54.

75. Bryant FB, Yarnold PR. Comparing five alternative factor-models of the student Jenkins activity survey: separating the wheat from the chaff. J Pers Assess. 1995;64:145-58.

76. Hair JF, Black WC, Babin BJ, Anderson RE: Multivariate Data Analysis. 2011.

77. Henson RK, Roberts JK. Use of exploratory factor analysis in published research common errors and some comment on improved practice. Educ Psychol Meas. 2006;66:393-416.

78. Tabachnick BG, Fidell LS. Using multivariate statistics: Pearson Education Limited; Harlow, 2013.

79. Costello AB, Osborne JW. Best practices in exploratory factor analysis: four recommendations for getting the most from your analysis. Pract Assess Res Eval. 2005;10:1-9.

80. Gie Yong A, Pearce S. Beginner's guide to factor analysis: focusing on exploratory factor analysis. Tutor Quant Methods Psychol. 2013:9:79-94

81. Beavers AS, Lounsbury JW, Richards JK, Huck SW, Skolits GJ, Esquivel SL. Practical considerations for using exploratory factor analysis in educational research; 2013. p. 18.

82. Cudeck R, MacCallum RC. Factor analysis at 100: historical developments and future directions. Mahwah: Lawrence Erlbaum Associates; 2007.

83. Pett MA, Lackey NR, Sullivan JJ. Making sense of factor analysis: the use of factor analysis for instrument development in health care research. California: SAGE Publications; 2003.

84. Courtney MGR. Determining the number of factors to retain in EFA: using the SPSS R-menu v2.0 to make more judicious estimations. ERIC. 2013;18:14.

85. Thompson B. Exploratory and confirmatory factor analysis: understanding concepts and applications. Washington, DC: American Psychological Association; 2004

86. Bollen $\mathrm{K}$, Stine RA. Bootstrapping goodness-of-fit measures in structural equation models. Sociol Methods Res. 1992;21:205-29.

87. Jackson DL, Gillaspy JA, Purc-Stephenson R. Reporting practices in confirmatory factor analysis: an overview and some recommendations. Psychol Methods. 2009;14:6-23.

88. Awang Z. Validating the measurement model: CFA. In: A Handbook on SEM. 2nd editiion ed: Kuala Lumpur: Universiti Sultan Zainal Abidin; 2015. p. 54-73.

89. Jaccard J, Wan CK. LISREL approaches to interaction effects in multiple regression. California: SAGE Publications; 1996.

90. Cheung GW, Rensvold RB. Evaluating goodness-of-fit indexes for testing measurement invariance. J Struct Equ Model. 2009;9:233-55.

\section{Ready to submit your research? Choose BMC and benefit from:}

- fast, convenient online submission

- thorough peer review by experienced researchers in your field

- rapid publication on acceptance

- support for research data, including large and complex data types

- gold Open Access which fosters wider collaboration and increased citations

- maximum visibility for your research: over $100 \mathrm{M}$ website views per year

At BMC, research is always in progress.

Learn more biomedcentral.com/submissions 